\title{
Data Fusion Between Microwave and Thermal Infrared Radiometer Data and Its Application to Skin Sea Surface Temperature, Wind Speed and Salinity Retrievals
}

\author{
Kohei Arai 1 \\ Graduate School of Science and Engineering \\ Saga University \\ Saga City, Japan
}

\begin{abstract}
Method for data fusion between Microwave Scanning Radiometer: MSR and Thermal Infrared Radiometer: TIR derived skin sea surface temperature: SSST, wind speed: WS and salinity is proposed. SSST can be estimated with MSR and TIR radiometer data. Although the contribution ocean depth to MSR and TIR radiometer data are different each other, SSST estimation can be refined through comparisons between MSR and TIR derived SSST. Also WS and salinity can be estimated with MSR data under the condition of the refined SSST. Simulation study results support the idea of the proposed data fusion method.
\end{abstract}

Keywords-data fusion; simulataneous estimation

\section{INTRODUCTION}

Microwave Scanning Radiometer: MSR onboard remote sensing satellites allow estimations of salinity, soil moisture, ocean wind speed, precipitable water, rainfall rate, air temperature (profile), atmospheric pressure, and Skin Sea Surface Temperature: SSST. On the other hands, Thermal Infrared Radiometer: TIR onboard remote sensing satellites allow estimations of SSST [1]. There are remote sensing satellites which carries both MSR and TIR radiometers such as Tropical Rainfall Measurement Mission: TRMM/VIRS (Visible to Thermal Infrared radiometer) and TMI (TRMM Microwave Imager) [2]. It is possible to improve estimation accuracy by using both radiometer data which is known as data fusion.

There are some atmospheric and ocean surface models in the microwave wavelength region. Therefore, it is possible to estimate at sensor brightness temperature (microwave radiometer) with the geophysical parameters. The real and the imaginary part of dielectric constant of the calm ocean surface is modeled with the SST, salinity (conductivity). From the dielectric constant, reflectance of the ocean surface is estimated together with the emissivity (Debue, 1929 [3]; Cole and Cole, 1941 [4]). There are some geometric optics ocean surface models (Cox and Munk, 1954 [5]; Wilheit and Chang, 1980 [6]). According to the Wilheit model, the slant angle against the averaged ocean surface is expressed by Gaussian distribution function.
There is a relation between ocean wind speed and the variance of the Gaussian distribution function as a function of the observation frequency. Meanwhile the influence due to foams, white caps on the emissivity estimation is expressed with the wind speed and the observation frequency so that the emissivity of the ocean surface and wind speed is estimated with the observation frequency simultaneously. Meanwhile, the atmospheric absorptions due to oxygen, water vapor and liquid water were well modeled (Waters, 1976 [7]). Then atmospheric attenuation and the radiation from the atmosphere can be estimated using the models. Thus the at-sensorbrightness temperature is estimated with the assumed geophysical parameters.

Sea surface temperature estimation methods with AMSR data are proposed and published [8] while ocean wind retrieval methods with AMSR data are also proposed and investigated [9]. Furthermore, water vapor and cloud liquid estimation methods with AMSR data are proposed and studied [10]. The conventional geophysical parameter estimation method is based on regressive analysis with a plenty of truth data and the corresponding microwave radiometer data [11].

Both radiometers observe same sea surface through same atmosphere. Also atmospheric model and sea surface model for both thermal infrared wavelength region and microwave wavelength region are known. Therefore, both radiometer data can be used for improvement of the estimation accuracy. One of the well known week points is sea surface emissivity model. As is mentioned above, surface emissivity depends on dielectric constant of the sea water as functions of sea surface temperature, salinity, etc., ocean wave shape distribution, foams (white caps appears when ocean wind is greater than 7 $\mathrm{m} / \mathrm{s}$ ), and so on.

The proposed method of data fusion between thermal infrared and microwave radiometers is eliminate influences due to emissivity changes by ocean winds based on the aforementioned models. Through simulation studies using Community Radiative Transfer Model: CRTM [12] of atmospheric code which covers from visible to microwave wavelength regions, it is found that the proposed data fusion is useful. 
The following section describes the proposed data fusion method followed by simulation studies. Then conclusion is described together with some discussion.

\section{PROPOSED METHOD}

\section{A. Process Flow of the Proposed Data Fusion Method}

Process flow of the proposed data fusion method is shown in Figure 1. Assuming both of TIR and MSR radiometers are onboard same remote sensing satellite and observe the same sea surface through the same atmosphere.

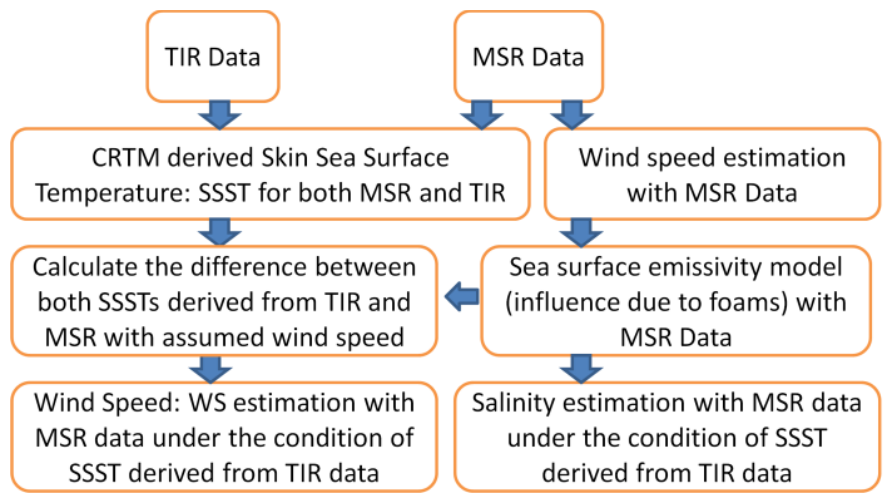

Fig. 1. Process flow of the proposed data fusion method

\section{B. Basic Idea of the Proposed Data Fusion Method}

SSST is estimated with both TIR and MSR data separately. There is discrepancy between both SSST_TIR and SSST_MSR due to the fact that influences on emissivity due to ocean wind speed are difference between both. Emissivity in TIR wavelength region is affected by wind speed a little while that in microwave wavelength region is changed so much. Moreover emissivity in MSR wavelength region may change SSST and salinity (in relatively lower frequency below $10 \mathrm{GHz}$ in particular). Therefore, such these influence might be possible to estimate by using the discrepancy between SSST_TIR and SSST_MSR. On the other hands, ocean wind speed can also be estimated with MSR data together with SSST. Therefore, wind speed can be refined using the discrepancy iteratively. Furthermore, salinity is estimated with estimated SSST as well as the refined wind speed.

\section{Theoretical Background}

Radiative transfer equation of MSR is expressed in equation (1).

$$
\begin{aligned}
I_{\nu}=\epsilon_{\nu} & B_{\nu}\left(T_{s}\right) \tau_{\nu}(0, Z, \theta)+\int_{0}^{z} B_{\nu}(T(z)) \frac{\partial \tau_{\nu}(z, Z, \theta)}{\partial z} d z \\
- & \left(1-\epsilon_{\nu}\right) \tau_{\nu}(0, Z, \theta) \int_{0}^{Z} B_{\nu}(T(z)) \frac{\partial \tau_{\nu}(0, z, 0)}{\partial z} d z
\end{aligned}
$$

The first term of equation (1) represent the contribution from the sea surface while the second term expressed the contribution from the atmosphere. The third term is the contribution from the reflected atmosphere and extraterrestrial contribution at the sea surface. In general, the first term is largest contribution followed by the second and the third term.

Sea surface reflectance for vertical and horizontal polarizations is expressed in equation (2) and (3), respectively.

$$
\rho v=\left|\frac{\epsilon_{r} \cos \theta-\sqrt{\epsilon_{r}-\sin ^{2}(\theta)}}{\epsilon_{r} \cos \theta+\sqrt{\epsilon_{r}-\sin ^{2}(\theta)}}\right|^{2}
$$

$\rho h=\left|\frac{\cos \theta-\sqrt{\epsilon_{r}-\sin ^{2}(\theta)}}{\cos \theta+\sqrt{\epsilon_{r}-\sin ^{2}(\theta)}}\right|^{2}$

where $\theta$ denotes observation angle, or incident angle. The sea surface reflectance is illustrated in Figure 2 as a function of incident angle. Meanwhile, sea surface emissivity in vertical and horizontal polarizations is represented in equation (4).

$$
\begin{gathered}
e v=1-\left|\frac{\epsilon_{r} \cos \theta-\sqrt{\epsilon_{r}-\sin ^{2}(\theta)}}{\epsilon_{r} \cos \theta+\sqrt{\epsilon_{r}-\sin ^{2}(\theta)}}\right|^{2} \\
e h=1-\left|\frac{\cos \theta-\sqrt{\epsilon_{r}-\sin ^{2}(\theta)}}{\cos \theta+\sqrt{\epsilon_{r}-\sin ^{2}(\theta)}}\right|^{2}
\end{gathered}
$$

Where $\varepsilon_{\mathrm{r}}$ denotes dielectric constant of sea water.

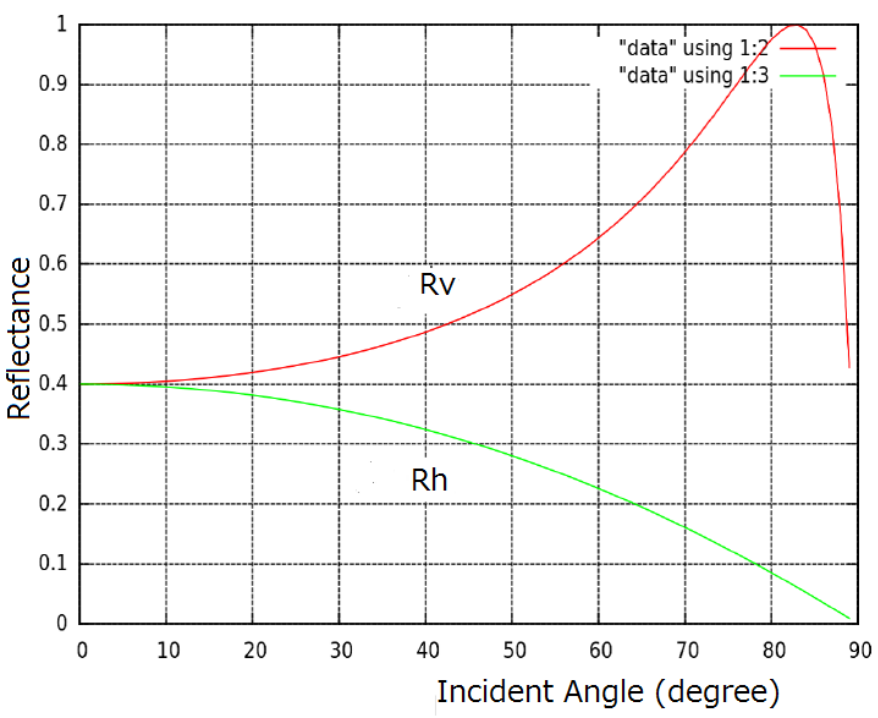

Fig. 2. Sea surface reflectance as a function of incident angle

\section{Simulation StUdiES}

\section{A. Radiance}

Simulation parameters are set as follows,

1) Wavelength: 11 micrometer for TIR, $5 \mathrm{GHz}$ for MSR

2) Atmospheric condition: US standard atmosphere 1976

3) Observation target: sea surface with $272 K, 282 K, 330 K$ of SSST

4) Observation zenith angle: 30 degree

Figure 3 shows calculated radiance using CRTM atmospheric software code while Figure 4 shows the radiance as a function of observation zenith angle. 


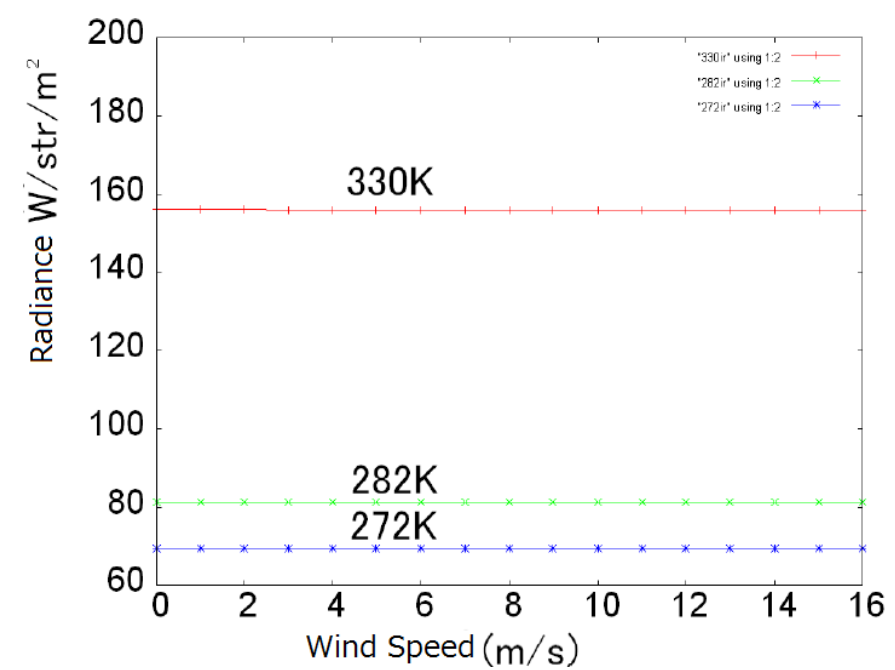

(a)TIR

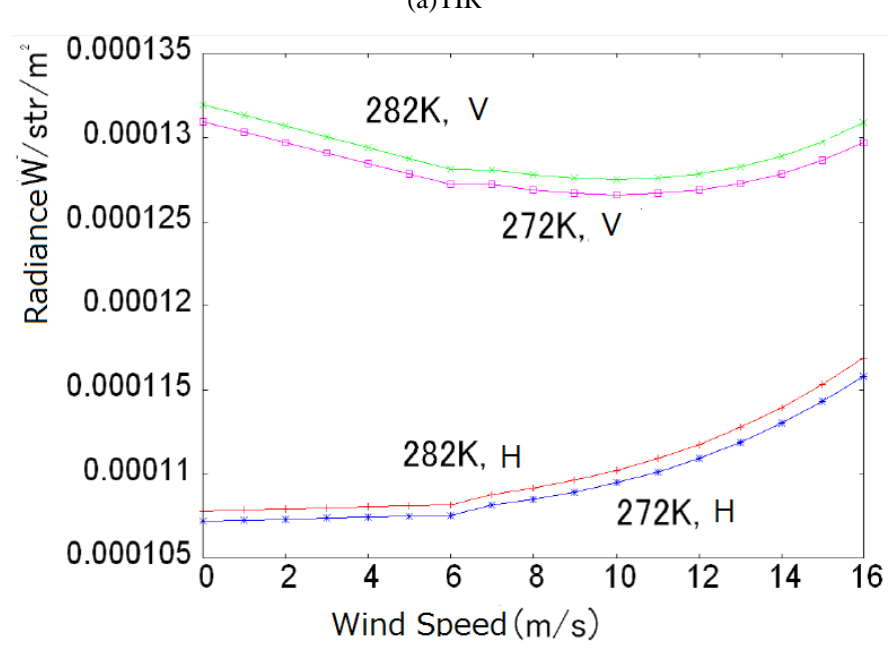

(b)MSR1

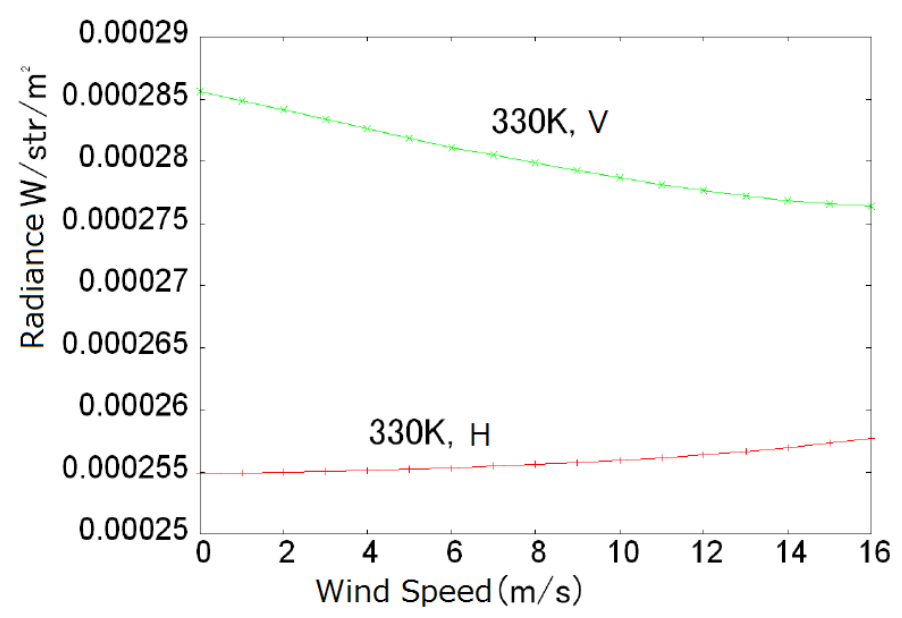

(c)MSR2

Fig. 3. Calculated radiance for TIR and MSR wavelength regions as a function of wind speed

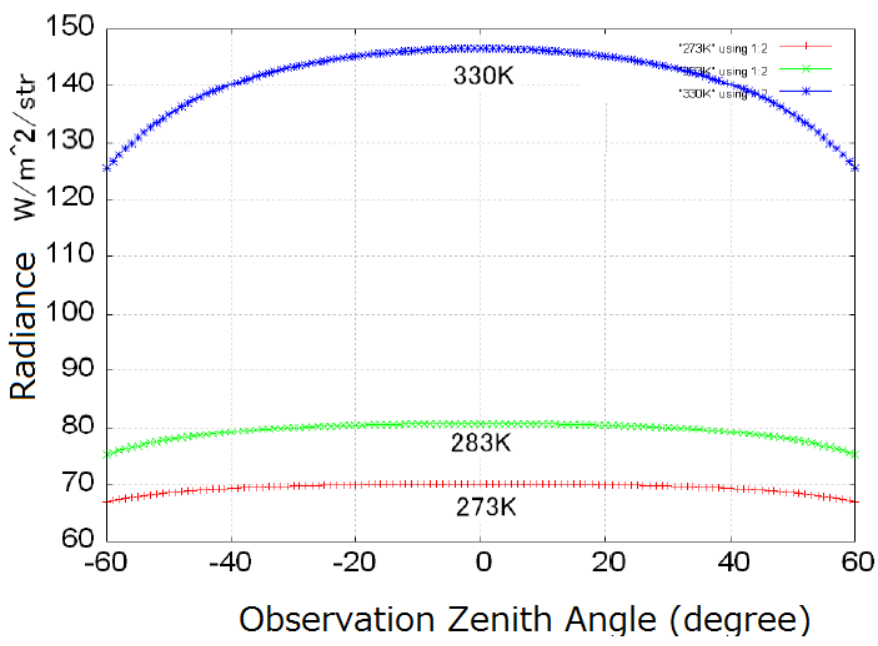

(a)TIR

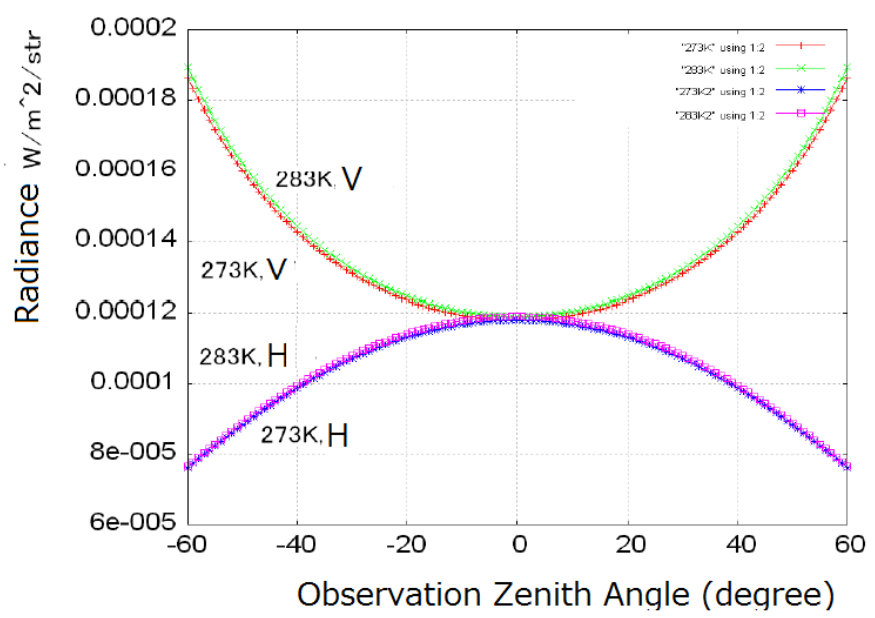

(b)MSR 1

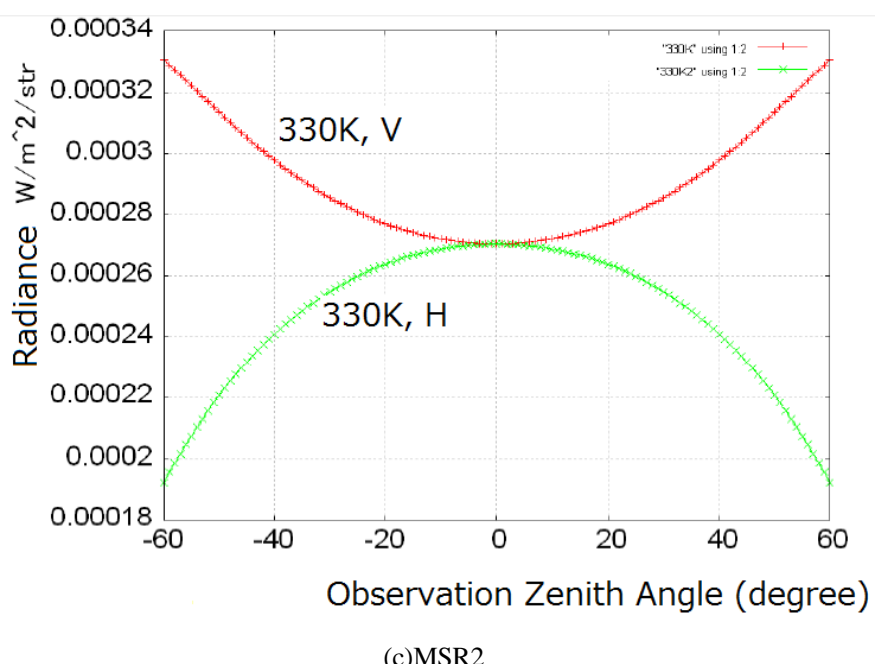

Fig. 4. Calculated radiance for TIR and MSR wavelength region as a function of observation zenith angle 
TIR radiance at large observation zenith angle, limb darkening appears. Meanwhile, Figure 5 shows calculated radiance with the parameters of wind speed ranged from 0 to $16 \mathrm{~m} / \mathrm{s}$.

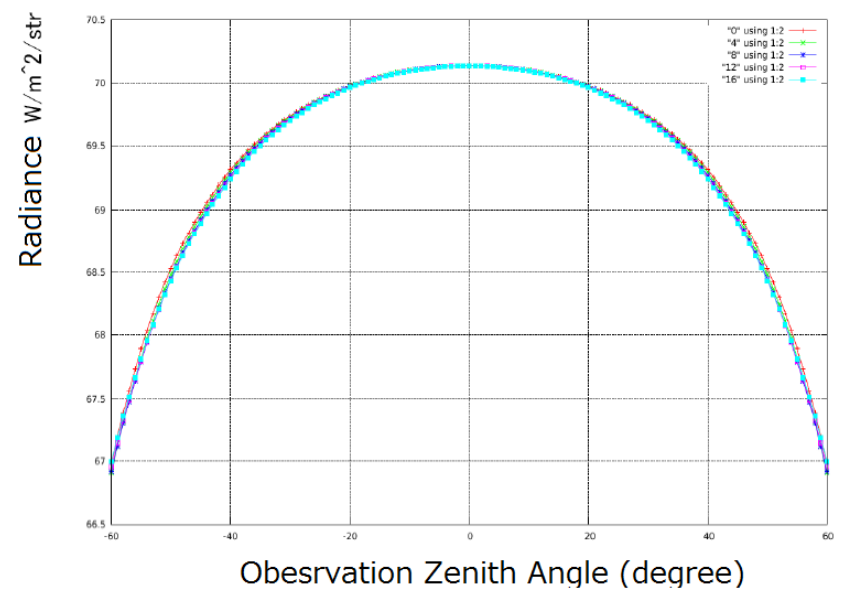

(a)TIR

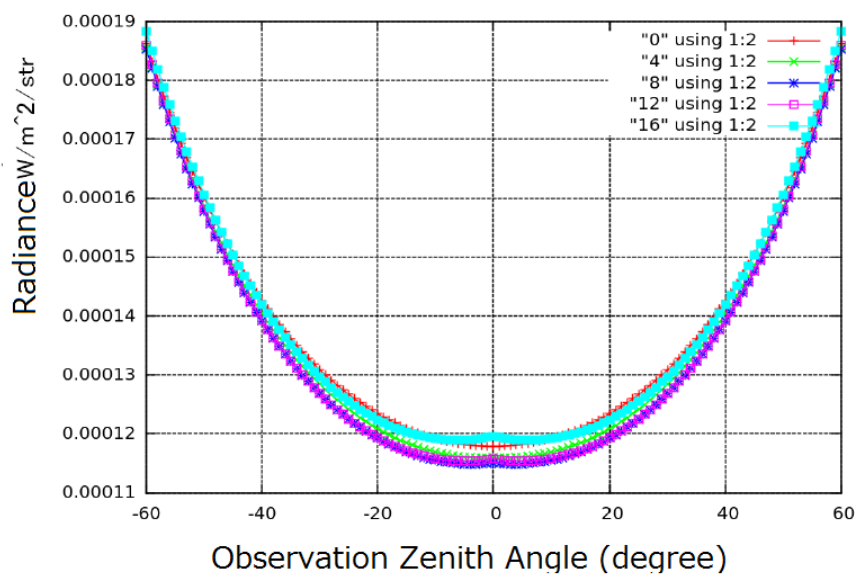

(b)MSR1

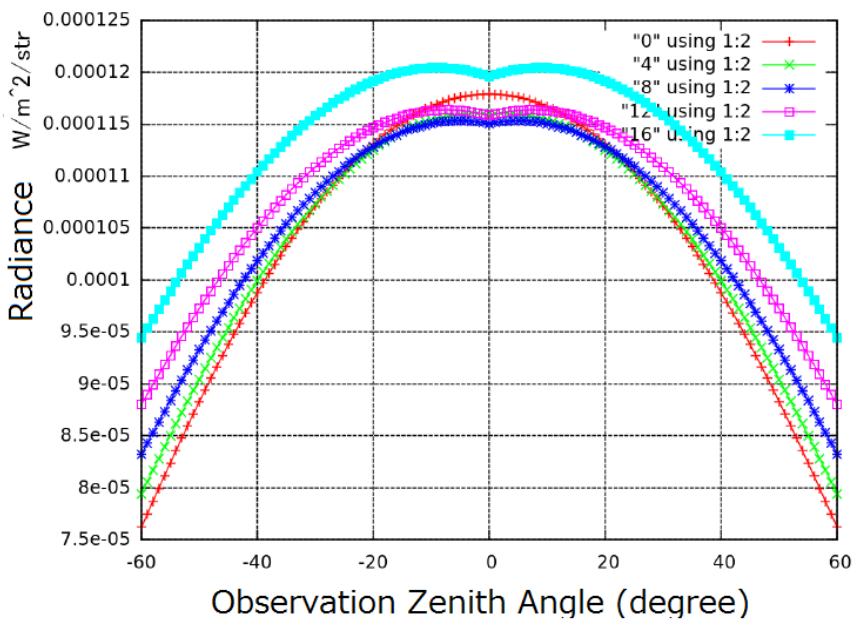

(c)MSR2

Fig. 5. Calculated radiance for TIR and MSR as parameters of wind speed ranged from 0 to $16 \mathrm{~m} / \mathrm{s}$
There is quite small difference among the calculated radiance for the different wind speed for TIR while that for MSR differ from each other, in particular for the $330 \mathrm{~K}$ of sea surface temperature (Figure 5 (c)). The relations between observation zenith angle and radiance depend on SSST.

Figure 6 shows the calculated radiance for nadir viewing of observation zenith angle as a function of wind speed. The relations between wind speed and radiance depend on SSST.

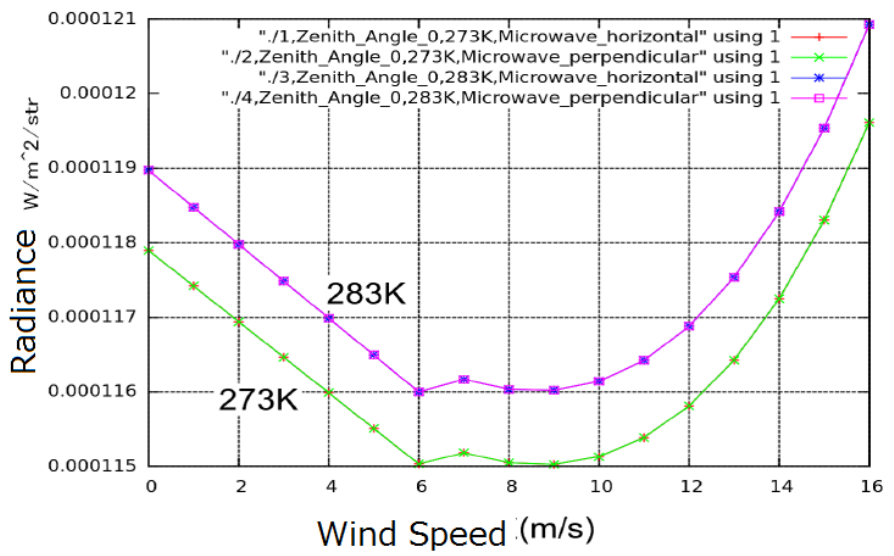

(a)MSR1

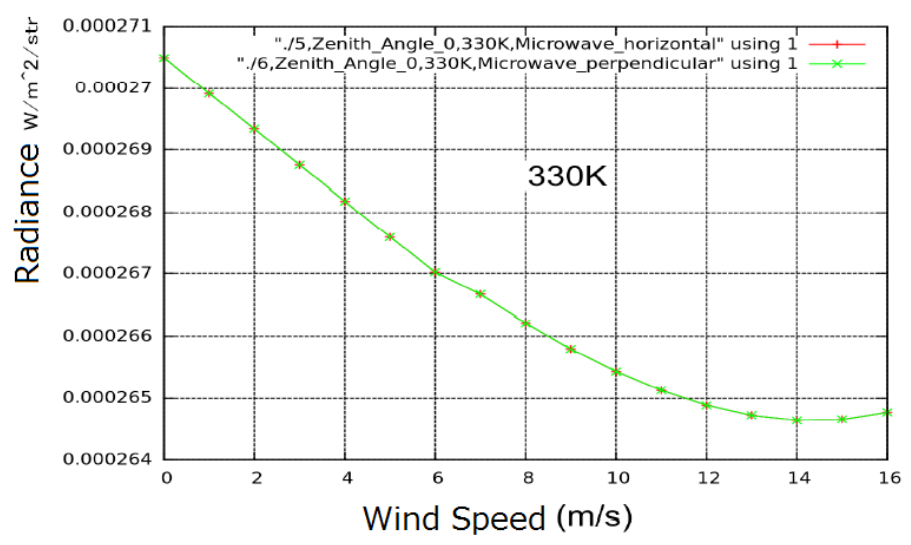

(b)MSR2

Fig. 6. Calculated radiance for nadir viewing of observation zenith angle as a function of wind speed

Meanwhile, Figure 7 shows calculated radiance as a function of salinity. It is obvious that there is no change of the calculated radiance for TIR while there is a relatively large change for MSR, in particular for vertical polarization. 


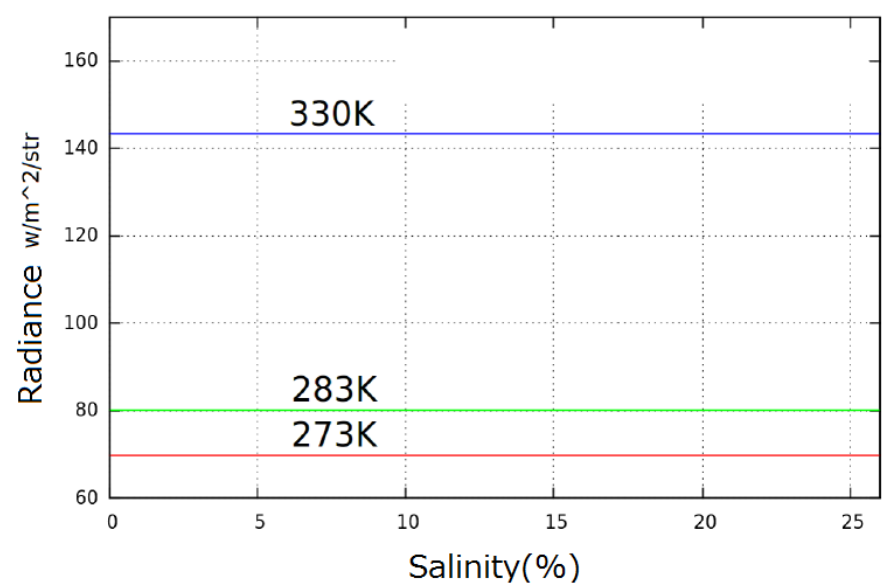

(a)TIR

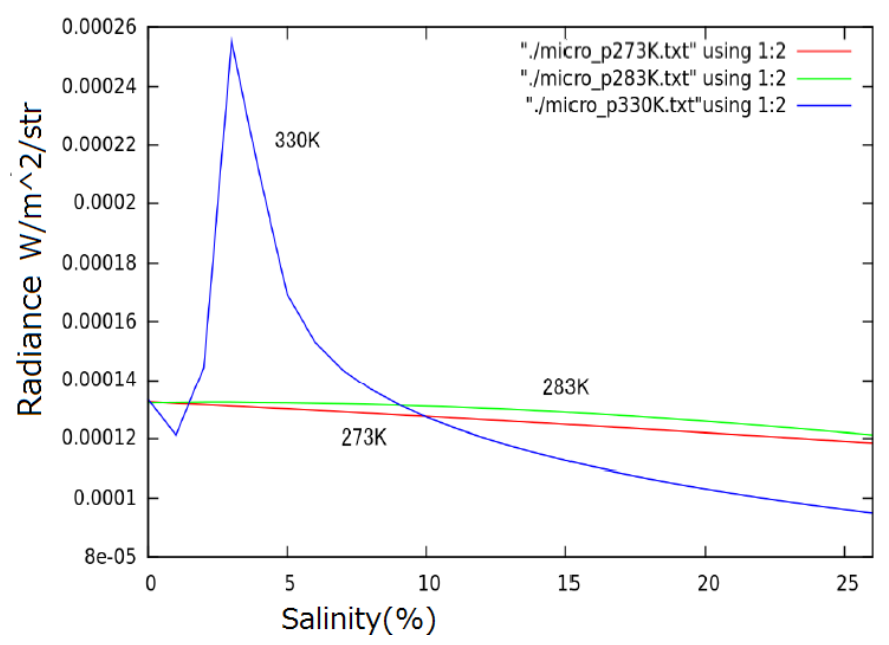

(b) Vertical polarization

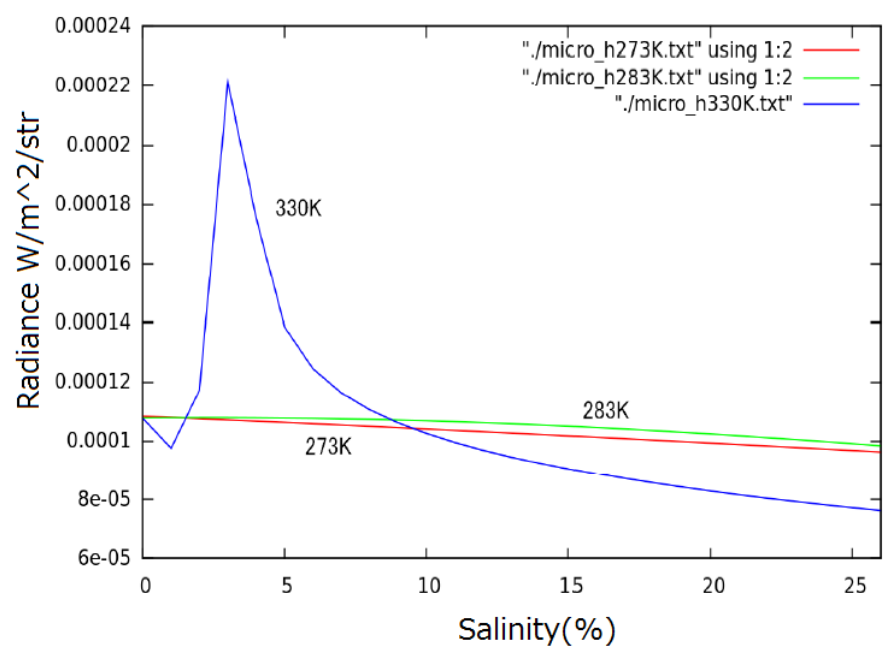

(c)Horizontal polarization

Fig. 7. Calculated radiance as a function of salinity

In more detail, calculated radiance for the salinity ranged from 2 to $4 \%$ is shown in Figure 8.

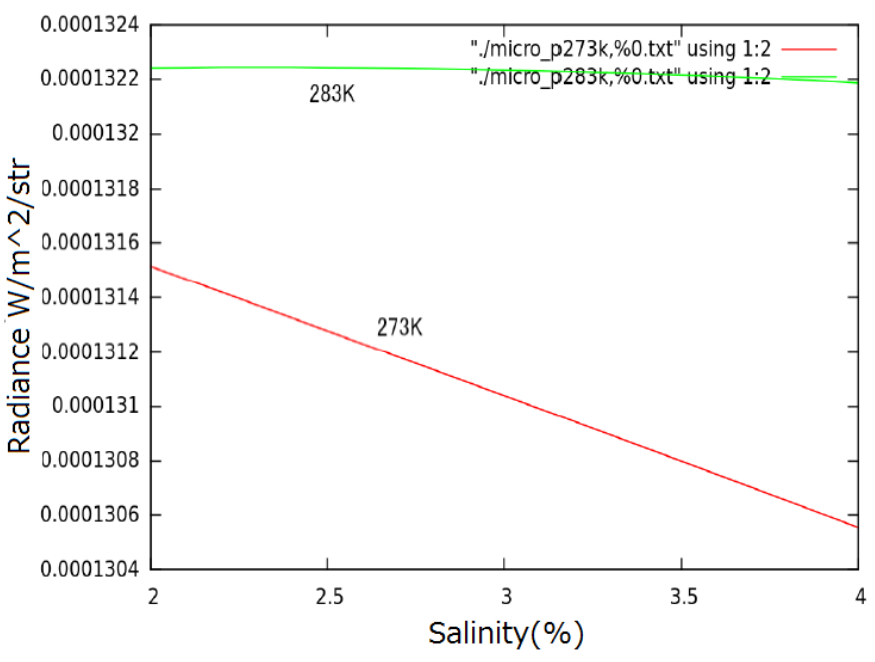

(a)Vertical polarization for 273 and $283 \mathrm{~K}$ of SSST

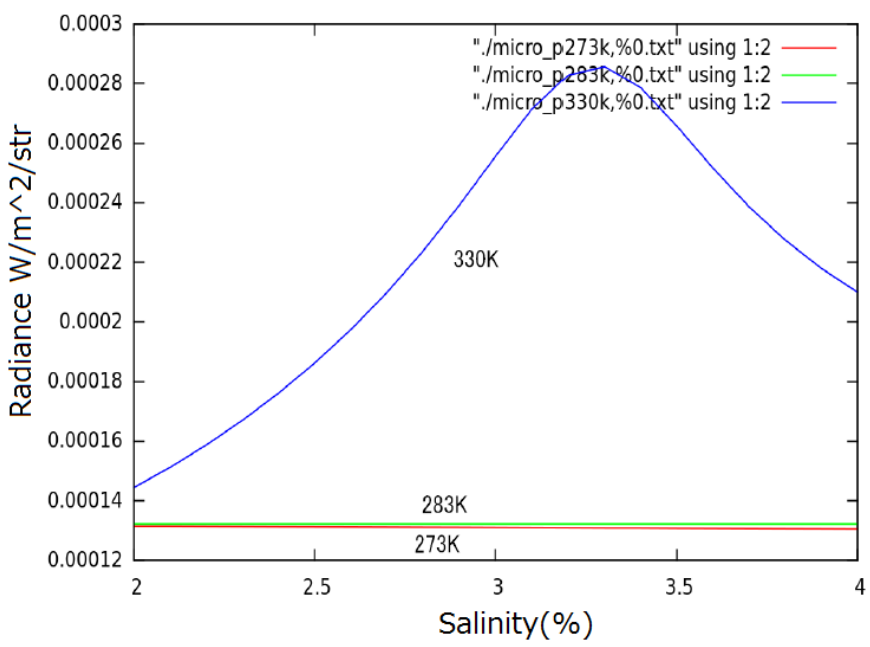

(b) Vertical polarization for 273, 283, and $330 \mathrm{~K}$ of SSST

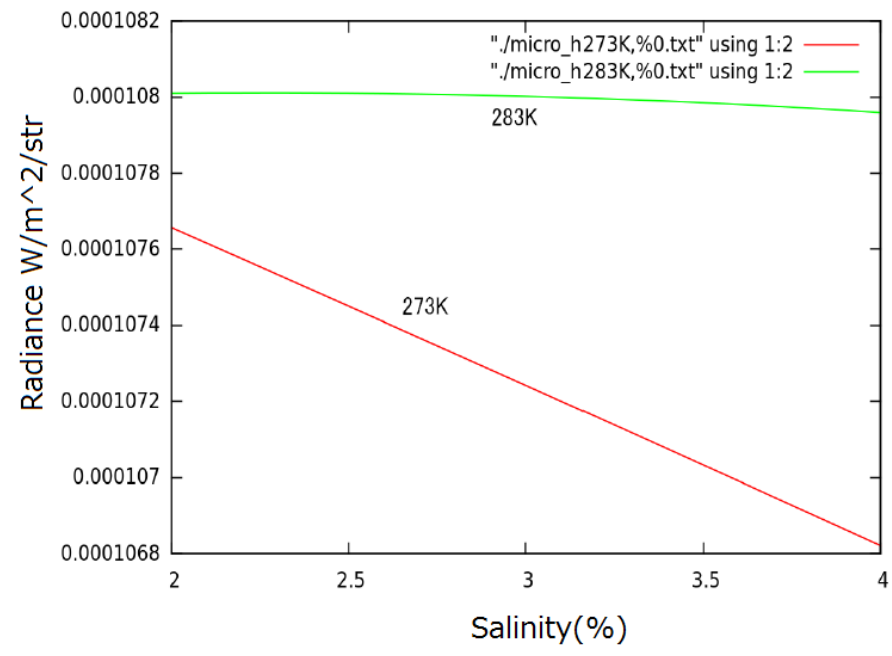

(c)Horizontal polarization for 273, 283K of SSST 


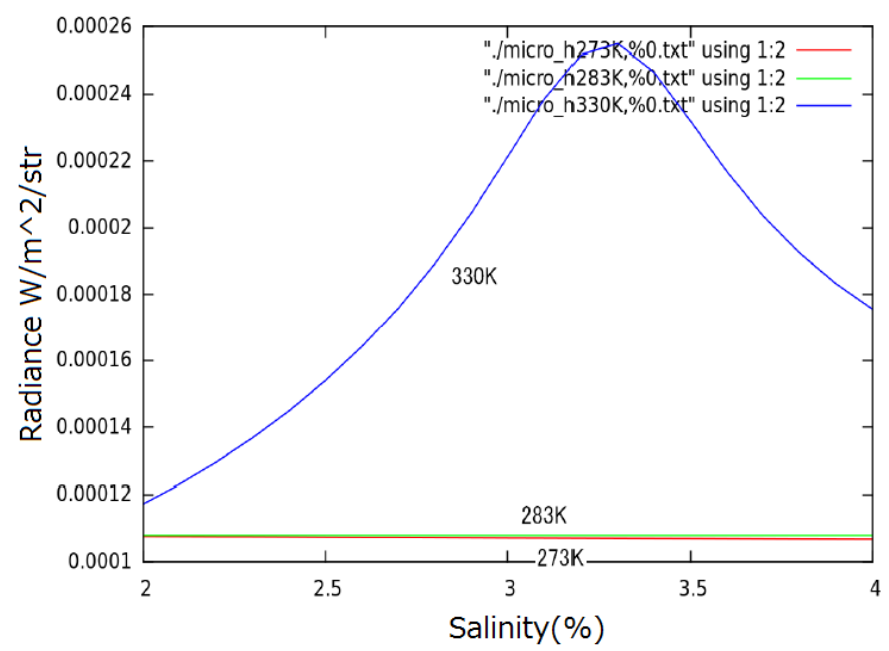

(d)Horizontal polarization for 273, 283, 330K of SSST

Fig. 8. Calculated radiance as a function of salinity

From these figure, it is found that salinity estimation is possible if the calculated radiance difference between horizontal and vertical polarization. Also it is promising that salinity is estimated for relatively large SSST, much greater than $330 \mathrm{~K}$.

\section{CONCLUSION}

Method for data fusion between Microwave Scanning Radiometer: MSR and Thermal Infrared Radiometer: TIR derived skin sea surface temperature: SSST, wind speed: WS and salinity is proposed. SSST can be estimated with MSR and TIR radiometer data. Although the contribution ocean depth to MSR and TIR radiometer data are different each other, SSST estimation can be refined through comparisons between MSR and TIR derived SSST. Also WS and salinity can be estimated with MSR data under the condition of the refined SSST. Simulation study results support the idea of the proposed data fusion method. In particular, SSST and WS can be estimated with refined SSST. Furthermore, it also is promising that salinity estimation with MSR data.

\section{ACKNOWLEDGMENT}

The author would like to thank Mr.Choyo Taura for his simulation studies.

\section{REFERENCES}

[1] K.Arai, Fundamental Theory on Remote Sensing, Gakujutu Tosho Publishing Co., Ltd.,

[2] K.Arai, Lecture Note on Remote Sensing, Morikita Publishing Co. Ltd.,

[3] Debue, R. Polar Molecules, Chemical Catalog, New York, 1929.

[4] Cole, K.S., Cole, R.H. Dispersion and absorption in dielectrics. J. Chem. Phys. 9, 341-351, 1941.

[5] Cox, C.S., Munk, W.H. Measurement of the roughness of the sea surface from photographs of the sun_s glitter. J. Opt. Sci. Am. 44, 838-850, 1954.

[6] Wilheit, T.T., Chang, A.T.C. An algorithm for retrieval of ocean surface and atmospheric parameters from the observations of the Scanning Multichannel Microwave Radiometer (SMMR). Radio Sci. 15, 525-544, 1980.

[7] Waters, J.R. Absorption and emission by atmospheric gasses. in: Meeks, M.L. (Ed.), Methods of Experimental Physics, vol. 12B.Academic, Orland, 1976 (Chapter 2.3).

[8] Dong, SF; Sprintall, J; Gille, ST, Location of the antarctic polar front from AMSR-E satellite sea surface temperature measurements, JOURNAL OF PHYSICAL OCEANOGRAPHY, Nov 2006, 2075-2089.

[9] Konda, M., A. Shibata, N. Ebuchi, and K. Arai, An evaluation of the effect of the relative wind direction on the measurement of the wind and the instantaneous latent heat flux by Advanced Microwave Scanning Radiometer, J. Oceanogr., vol. 62, no. 3, pp. 395-404, 2006.

[10] Cosh, M. H., T. J. Jackson, R. Bindlish, J. Famiglietti, and D. Ryu, A comparison of an impedance probe for estimation of surface soil water content over large region, Journal of Hydrology, vol. 311, pp. 49-58, 2005.

[11] Wentz, F. AMSR Ocean Algorithm, second version of ATBD, NASA/GSFC, 2000.

[12] Yong Han, Paul van Delst1, Quanhua Liu1, Fuzhong Weng, Banghua Yan, Russ Treadon and John Derber, JCSDA Community Radiative Transfer Model (CRTM) - Version 1, NOAA Technical Report NESDIS 122

\section{AUTHORS PROFILE}

Kohei Arai, He received BS, MS and PhD degrees in 1972, 1974 and 1982, respectively. He was with The Institute for Industrial Science, and Technology of the University of Tokyo from 1974 to 1978 also was with National Space Development Agency of Japan (current JAXA) from 1979 to 1990. During from 1985 to 1987 , he was with Canada Centre for Remote Sensing as a Post Doctoral Fellow of National Science and Engineering Research Council of Canada. He was appointed professor at Department of Information Science, Saga University in 1990. He was appointed councilor for the Aeronautics and Space related to the Technology Committee of the Ministry of Science and Technology during from 1998 to 2000 . He was also appointed councilor of Saga University from 2002 and 2003 followed by an executive councilor of the Remote Sensing Society of Japan for 2003 to 2005. $\mathrm{He}$ is an adjunct professor of University of Arizona, USA since 1998. He also was appointed vice chairman of the Commission "A" of ICSU/COSPAR in 2008. He wrote 30 books 